Accepted manuscript of the article published in: Ginovart Cid C, Colominas C, Oliver A. Language industry views on the profile of the post-editor. Translation Spaces. 2020 Jan 14. DOI:

10.1075/ts.19010.cid

\title{
Language industry views on the profile of the post-editor ${ }^{1}$
}

\author{
Clara Ginovart Cid*
}

Carme Colominas*

Antoni Oliver**

*Universitat Pompeu Fabra and **Universitat Oberta de Catalunya

\section{Abstract}

The more language service companies (LSCs) include machine translation post-editing (MTPE) in their workflows, the more important it is to know how the PE task is performed, who the post-editors are, and what skills they should have. This research is designed to address such questions. It aims to deepen our knowledge of current practices to later create new training content and adapt existing training methodologies to different types of audiences. Based on the results of a survey of LSCs and other companies who currently use MTPE, we present a picture of evolving practices in the contemporary European MTPE market, and opinions held about this emerging métier. Our research finds that a high level of expertise in MTPE may not necessarily be indicative of the industry, and that the post-editor of MT has a hybrid and transdisciplinary profile.

\section{Keywords}

MTPE, post-editing, quality evaluation, machine translation, skill set, language industry

\section{Introduction}

In recent years, machine translation (MT) and post-editing (PE) have had an increasing presence in the translation industry due in large part to the fact that the quality of MT has

\footnotetext{
${ }^{1}$ The present research is carried out in the framework of Government of Catalonia's grant Doctorats Industrials
} 
improved significantly with the advent of phrase-based statistical MT and, more recently, neural MT (NMT). As pointed out in the 2018 edition of the European Language Industry Survey: "2018 is clearly the year of machine translation. This is the first year that more than half of the respondents declare that they are using the technology in one way or another" (EUATC et al. 2019).

The fact that NMT is producing high-quality results, mainly in terms of fluency (Castilho et al. 2017), along with the fact that most NMT toolkits are easily accessible with userfriendly licenses (Forcada 2017), is having an impact on the further expansion of MT. Undoubtedly, this technology will be used for more language pairs and subject domains as more and more data becomes available. So, the percentage of translation projects carried out via machine translation post-editing (MTPE ${ }^{2}$ ) will presumably keep increasing in coming years. However, while the PE task is becoming increasingly necessary, it is also becoming more difficult, and the cognitive effort involved should not be underestimated (Rossetti and Gaspari 2017 and Popović et al. 2014, among others). New professional skills ${ }^{3}$ are needed, but it is still not clear what these skills are or how language professionals should be trained to acquire them, nor how LSCs may assess them.

As has been analyzed and demonstrated in studies such as those by Vasconcellos (1986), Green et al. (2013), and Daems et al. (2016), for some language pairs and text types, MTPE may require less time than human translation "from scratch," without negatively affecting product quality. This fact has been key for this type of translation workflow to occupy a place among the services offered by LSCs and language professionals alongside human translation. Naturally, this change has had an impact on all agents involved: LSCs, ${ }^{4}$ language professionals, MT developers and companies, and end users. Numerous studies have contributed to the evaluation of this impact, with many aiming to find out

\footnotetext{
${ }^{2}$ Note that the alternative, commonly encountered abbreviation, 'PEMT', was used in our survey.

3 "Skill" is understood as defined in Merriam Webster 1a: the ability to use one's knowledge effectively and readily in execution or performance or 2: a learned power of doing something competently: a developed aptitude or ability.

${ }^{4}$ We understand "language service company" as defined by Elia as: an organization that provides language services on a full-time basis to paying clients and employs two or more persons, owner included. We avoid using the term "language service provider" (LSP) as it is defined by BS ISO 17100:2015: person or organization who provides language-related services. To refer to a single person we use the term "language professional" or "post-editor."
} 
the degree of implementation of MT and PE in the market. In a survey carried out by TAUS among LSCs in Europe, America and Asia about the use of MTPE in 2010 (when NMT did not yet exist), it was found that, out of the 75 companies that responded to the survey, almost half (49.3\%) offered MTPE services (Joscelyne and Brace 2010). The MT Market Report 2014 (van der Meer and Ruopp 2014) showed that 38.63\% of respondents offered MT services within an overall framework of $6.23 \%$ annual translation growth. In the global series Translation Technology Insights Research 2016 (SDL 2016), SDL surveyed 2,784 freelancers, providers and corporations, and the results showed that $40 \%$ use MT. Obviously, such changes in established translation procedures have an impact on the market, which has already resulted in new standards. BS ISO 17100 (2015) defined $\mathrm{PE}$ as a professional activity in the context of translation services. The new job profile associated with this activity was established with the publication of BS ISO 18587 (2017).

The American Translators Association's (ATA) Position Paper on Machine Translation (2018) finds that most translators have realized that MT is one valuable tool among others that can be used to assist with translation projects. Furthermore, it states that "one more qualification [is looked for] in a suitable translator: someone who can evaluate the potential benefit of using machine translation, can provide guidance in a choice of a system, and knows how to use it to [the] mutual benefit [of translators and purchasers]." The integration of MTPE in translation workflows, also favored by developments such as adaptive machine translation (ATA 2018) and investigated in many instances of translation process research, has in turn had an impact on the translator's competency profile. It has been established that the boundary between translation memory (TM) and MT has become blurred "with MT-assisted TM translation" (Bundgaard and Christensen 2019, 15), so maybe all translators will one day become post-editors, as foreseen by Pym (2013). Regardless of questions such as whether the translator's profile and the post-editor's profile should be differentiated or to what extent, it is a fact that new tasks have emerged which require language experts to master specific skills. And skills require training. Hence, it comes as no surprise that studies on MTPE and the post-editor profile represent a growing field. However, to the best knowledge of the authors, no attempt has been made to reflect on the distribution of workload concerning tasks: is the 
post-editor a translation professional who spends 7 to 9 hours per day mending MT/TM output? To what extent does MTPE require a trans- or multidisciplinary skill set? And how many other PE-related tasks does a post-editor usually perform? Our questionnaire has been designed to address these issues. In particular, we wish to answer the following research questions:

RQ1: To what extent is the position of MT post-editor hybrid and transdisciplinary?

RQ2: Is it possible to define an MTPE expertise level which could be indicative of both best practices in and the evolution of the industry?

Theoretical contributions have mainly tackled the definition and importance of PE specific skills. For this reason, we have relied on the previous work by authors such as O’Brien (2002), Guerberof et al. (2012), Pym (2009 ; 2013), O’Brien et al. (2014), Marheinecke (2016), Juarros (2017), Absolon (2018), and Cid-Leal et al. (2019), among others, to build a predetermined list of eleven PE skills (cf. section 3). O'Brien (2002) offers a good review of existing research on the PE skill set, and she is the first to put forward a course proposal within the academia. Austermühl (2013) and Pym (2013) built on the work of the EMT Expert Group and made very relevant contributions to the field, as did the PACTE group (2014). One noteworthy competency model has been set up by the EDI-TA research group (Rico and Díez Orzas 2013a, b). Doherty and Gaspari (2013), for example, emphasize the ability to find a balance between PE speed and invested effort with respect to required quality as a key skill, while other authors (Zaretskaya 2017) prioritize the ability to decide whether a segment should be post-edited or translated from scratch.

To define the predetermined list of fourteen PE tasks that is commented on in section 3, we have drawn inspiration from the aforementioned sources, as well as work by Krings and Koby (2001), Bernth and Gdaniec (2001), Allen (2003), Van Ess-Dykema et al. (2010), Temizöz (2016), and Sánchez-Gijón (2016), among other authors. Some authors have, like us, relied on survey-based research, for instance, Tatsumi (2010), Mesa-Lao (2014), Gaspari et al. (2015), do Carmo (2017), Vintar et al. (2017), Vieira and Alonso (2018) and Blagodarna (2018). Sycz-Opoń and Gałuskina (2017) not only looked at the PE process and reflected on it using questionnaires but also put forward a MT Evaluation 
Protocol that seems to have been integrated as a 'feedback form' by some LSCs (Guerrero 2017).

Although, in general, training centers do not yet respond to the needs of the market (CidLeal et al. 2019; Jia et al. 2019), curricula of some universities (mainly at master's level) already include content about MTPE (Plaza Lara 2019). Koponen (2018), for example, shares her experience in building a PE course module. The localization master's curriculum at the Universitat Autònoma de Barcelona (UAB) also includes training on MT and PE (Guerberof and Moorkens 2019). The DigiLing PE course is an ongoing effort and just one more example of MTPE course development within academia (DigiLing n.d.). Finally, the eight PE sub-competences and the PE competence model recently published in The Journal of Specialised Translation by Nitzke et al. (2019) are a very welcome contribution to the field. From a practical perspective, in the market, MTPE training plans have been developed and implemented, for example, at ASAP Translations (Absolon n.d.) and TransPerfect (Zaretskaya 2017). Absolon (2018) identifies the post-editor as one of the roles of translation professionals, and he proposes a training plan with various exercises to develop the three groups of skills in the competency model designed by the author (linguistic, technical, and decision-making). Other industry players, such as SDL (n.d.), KantanMT (n.d.), and TAUS (van der Meer 2015), also offer online MTPE training courses. The sources presented in this paragraph along with the questionnaire designed by the POST-IT network (Tradumàtica Research Group n.d.) and other authors' work (Torrejón and Rico 2002; Calvo 2009; Rico and Torrejón 2012; Guerberof 2013; Doherty and Kenny 2014; Koponen 2015; Moorkens and O'Brien 2017) have helped us build the predetermined list of fifteen training elements (cf. section 3).

Skills and tasks are intrinsically interrelated; and it is common knowledge that traditional hiring practices are based on qualification level and previous experience. Thus, to create the list of seventeen predefined recruitment criteria for hiring post-editors (cf. section 3), we have sought inspiration in the literature discussed above, focusing particularly on BS ISO 17100:2015 and BS ISO 18587-2017. We have also drawn inspiration from Egdom et al. (2018). 
In the present article we offer a detailed quantitative analysis of key questions on the professional profile of the post-editor. The analysis is based on survey data and it will focus on the following aspects: (1) tasks with which post-editors in real professional scenarios are faced, (2) criteria that LSCs take into consideration when hiring a posteditor, (3) skills most valued in professional post-editors, ${ }^{5}$ and (4) training content covered in current plans created by LSCs.

The article is structured as follows: In section 2 we describe how the questions were designed, and how the questionnaire was disseminated, and we present the profile of the respondents. In section 3 we set out our lists of PE-related tasks, recruitment criteria, skills and training elements. The discussion (section 4) is divided into four subsections: 4.1 presents the results on PE-related tasks; 4.2 presents the results on recruitment criteria; PE skills are discussed in 4.3; and we consider the survey results about training content in 4.4. Finally, we present our conclusions in section 5.

\section{Survey Methodology}

To address the research questions presented in section 1 as comprehensively as possible, special attention has been paid to research design. As already indicated, based on previous literature, we propose a list of fourteen tasks related to PE, seventeen recruitment criteria, and eleven skills a professional post-editor needs to have, to shed light on our research questions. With regard to training content, we devise a list of fifteen elements a MTPE course might cover. This set of proposals will be explored in greater detail in section 3. Furthermore, we approach our object of enquiry in greater detail than has been the case in previous research: a fine-grained categorization of tasks and skills is made, for example, with tasks divided into Main Tasks, Secondary Tasks, or Occasional Tasks, and a five-point Likert scale is used for evaluating the importance of skills. In addition, we establish an LSC's degree of expertise in PE by combining their experience (in years) in PE with the percentage of translation projects that an LSC carries out using MTPE. The three expertise levels are named 'Beginner', 'Intermediate', and 'Advanced'.

\footnotetext{
${ }^{5}$ Skills are here defined as 2: a learned power of doing something competently: a developed aptitude or ability (Merriam Webster).
} 
The questionnaire title is Machine Translation and Post-Editing in the Industry, and it is addressed to LSCs or companies with a translation department. However, we cannot claim that our results are representative of the latter, since the vast majority of valid submissions come from LSCs.

The questionnaire was created using the online form builder Jotform. ${ }^{6}$ In it we ask, from different perspectives, a series of multiple-choice questions tackling our core topics. We include control questions and we phrase the questions in a way that avoids negative (or positive) interpretation of a given answer to limit the risks of bias and untruthfulness (Gile 2006; Oncins de Frutos 2008; Vehovar et al. 2019). Moreover, Jotform allows us to configure some questions as mandatory, and some as optional. Similarly, respondents are led to relevant sections of the questionnaire based on their profiles. The Applied Statistics Service of the Universitat Autònoma de Barcelona produced an evaluative report on the questionnaire and we followed their counsel, for instance, by randomizing the longest answers to avoid the risk of influencing the responses of participants and adding a progress bar indicator. A pilot survey with 15 participants was completed to adjust the wording and distribution of questions and answers before launching the survey. Probabilistic and convenience sampling methods were used to reach maximum representation. With a focus on Europe, the questionnaire was disseminated in early December 2018, by email, to over 200 European groups, associations, and firms. ${ }^{7}$ It was also published on leading social media platforms, such as LinkedIn, Twitter and Facebook (posted on the personal profiles of the authors and shared in public and closed translation and localization groups). A reminder was set for early January 2019, and submissions were accepted until the beginning of February.

\subsection{Questionnaire Design}

The questionnaire was designed in late 2018 in Jotform ${ }^{8}$ and contains 81 questions that can be filled out in approximately 15 to 20 minutes. It is divided into seven sections:

1. Basic Information. Here we collected the respondents' demographic data.

\footnotetext{
${ }^{6}$ https://www.jotform.com/

${ }^{7}$ The groups and associations not already known to the authors were browsed on the Internet, for instance in the list provided by Hyperion LTd. (n.d.). The LSCs that were contacted directly by email came from public lists and reports by Common Sense Advisory, such as the 2016 edition of Top 100 Language Service Providers (Henderson, 2016).

${ }^{8}$ The form can be accessed here: https://form.jotformeu.com/82863740587368
} 
2. MTPE Projects. Here we defined the concept of 'post-editing' according to BS ISO 18587-2017:

"MTPE (machine translation post-editing) is defined as 'editing and correcting machine translation output'. Machine translation is defined as 'automatic translation of text from one natural language to another using a computer application'."

We also filter here for the right audience. More specifically, if the respondent answers 'No' to the question "Does your company handle translation projects with post-editing of machine translation?", the survey comes to an end and s/he is invited to submit.

3. Client-TSP ${ }^{9}$ Agreement. This section is only visible to LSCs, not to firms with a translation department.

4. Current Trends in MTPE Projects. This section is subdivided as follows:

- MTPE Background, which enquires about the LSC's background in MTPE; e.g. language pairs, the reason for using MT, PE and revision levels, and controlled authoring. - MT Post-Editors' Profile, ${ }^{10}$ which covers three of the core topics (cf. section 3) that are discussed in the present article, namely: the tasks performed by in-house and freelance post-editors, the recruitment criteria of the firm or LSC, and the rating of skills according to the respondents' beliefs.

- The MT Post-Editing Project. In this section we inquire about workflows and procedures involving how MTPE projects are handled; e.g. the PE assignment (if different from the translation assignment), PE guidelines, PE feedback, and translation quality assessment (TQA).

5. Training in MTPE. Here we inquire if the company provides training on MT, either to in-house staff or to freelance collaborators, and how it is provided. We also investigate one of the core topics (cf. section 3) presented in this article, namely the MTPE training content.

\footnotetext{
${ }^{9}$ Translation Service Provider defined as "language service provider that delivers translation services" (BS ISO 18587:2017) and is considered as a synonym of "LSC" in this article.

${ }^{10}$ Even if the entire questionnaire is centered on MTPE, the authors also consider translators who use CAT tools where MT is integrated to be post-editors. Nonetheless, the authors rely on the respondents' own perceptions on which of their employees are 'post-editors'.
} 
6. Technology and Tools. Here we collect information on the Computer Aided Translation (CAT) tools and MT systems used. It is subdivided in two parts ('TM/MT not integrated' and 'Integrated TM/MT').

7. Feelings and Thoughts. Here we ask the respondents their opinions on the maturity of existing courses on MTPE. We also ask if they would potentially like to have access to an online platform to submit MTPE projects to trainees (a sort of virtual internship). Finally, we collect information on the awareness of the industry regarding standards such as BS ISO 18587:2017.

At the end respondents are invited to add any comments they may have and leave their contact details if they consent to be contacted to further discuss topics of the questionnaire. They can also ask for a report with the results.

\subsection{Profile of the Respondents}

We received 66 valid submissions. The respondents are based in 19 different countries, mostly in Spain (17), but also in France (6), Poland (5), Germany (5), the Netherlands (4), Portugal (3), Greece (3), the Czech Republic (3), Slovenia (2), Switzerland (2), Romania (2), Italy (2), Ireland (2), Russia (2), Hungary (1), Belgium (1), the United Kingdom (1), Turkey (1), the United States (1), and Argentina (1). Two respondents did not disclose their country of residence. Even though a large proportion of the participants (26\%) is based in Spain, this has no effect on the results, since the comparison between the survey data analyzed only for Spain, and the analysis for the rest of the countries did not show statistically significant variations. The positions held by the respondents are presented in Table 1:

\begin{tabular}{|l|l|}
\hline Job position & Number of respondents \\
\hline Project management & 23 \\
\hline Executive management & 20 \\
\hline MT specialist & 10 \\
\hline Linguist or paralinguist & 9 \\
\hline Researcher & 3 \\
\hline Not disclosed & 1 \\
\hline
\end{tabular}

Table 1. Respondents' positions

The majority of the respondents are small LSCs (only 12\% of the respondents [8] are firms with a translation department). Indeed, $68 \%$ of the 66 respondents have fewer than 
50 employees. $76 \%$ of the respondents handle less than $25 \%$ of their translation production via MTPE, which makes us wonder if an overview of different levels of "MTPE expertise" of the participants can be drawn up. If we look at the years of experience in MTPE, our respondents have mostly one and five years' experience (55\%), and 29\% of them have been working with MTPE for more than five years. We combine workload (question 15. What is the percentage of your translation production via post-editing of machine translation? whose possible answers are ' $25 \%$ or less', 'Between 26\% and 50\%', 'Between 51\% and 75\%', and 'More than 76\%'11) with experience (question 14. How long have you been handling MTPE projects? whose possible answers are 'Less than 1 year', 'Between 1 and 5 years', and 'More than 5 years ${ }^{12}$ ) by multiplying the values attributed to each answer. This results in an expertise scale from ranging from 1 to 12 . For the purposes of statistical analysis of the collected data, we have distributed these levels over three groups:

\begin{tabular}{|l|l|l|}
\hline Name & Value & Percentage of respondents \\
\hline Beginner & 1 & $11 \%$ \\
\hline Intermediate & 2 and 3 & $65 \%$ \\
\hline Advanced & 4 to 12 & $23 \%$ \\
\hline
\end{tabular}

Table 2. Classification in PE expertise groups

The 'Beginner' group is formed by the respondents who had less than one year of experience and post-edit less than $25 \%$ of their translation projects (11\% of the respondents); the 'Intermediate' group is formed from all the possible combinations resulting in values 2 and 3 (65\% of the respondents); and the 'Advanced' group represents all the combinations resulting in values from 4 to 12 (24\% of the respondents). Considering that the increase in offering MTPE services is relatively recent, it is difficult to distribute the levels to obtain balanced numbers of representatives for each group; the Intermediate group is thus the biggest.

The fact that it is mainly small LSCs (68\% of our respondents having fewer than 50 employees) who were interested in such survey-based research, along with the large number of respondents who obtain a score of 2 or 3 (Intermediate group), suggests that

\footnotetext{
${ }^{11}$ Each of the four possible answers is assigned a value from 1 to 4 .

${ }^{12}$ Each of the three possible answers is assigned a value from 1 to 3 .
} 
small LSCs are trying to gain expertise in MTPE. Hence, there is a real need to identify in which ways MTPE practice can be improved, and we suggest that current methods and workflows of the 'Advanced' group of the industry may represent the model to follow.

\section{The Questionnaire's Core Topics}

In this section, we lay out the main subject matter included in parts 4 and 5 of the questionnaire and we justify the selection of tasks, recruitment criteria, skills and training content. We will focus our attention on questions 34 and 35, which handle the PE-related tasks; on question 38, on recruitment criteria; on question 39, which discusses the eleven PE-related skills; and on question 52, which researches training content. In each case, we describe how the MTPE expertise level (Beginner, Intermediate, or Advanced) of the LSC may affect their practice, as our assumption is that this expertise level informs the workflows and procedures used by the industry stakeholders.

As already indicated, a total of fourteen tasks were included in questions 34 and 35 (cf. Appendix 1) to see which ones are most relevant to a post-editor's profile and to what extent that profile is a hybrid profile. Either question 34 ("What workload do the following PE tasks represent for your in-house post-editors?") or question 35 ("What workload do the following PE tasks represent for your freelance post-editors?") would appear according to the respondent's previous answer to how many professionals of each status their firm works with. If both, s/he would be asked to fill out the two questions. The respondent could choose among three possible workload categories for each task (Main task, Secondary task, or Occasional ${ }^{13}$ task) ${ }^{14}$, or 'N/A' or leave a task empty if the post-editors never carry out such activities ${ }^{15}$. The respondent was not limited regarding the number of Main, Secondary or Occasional tasks that s/he could choose.

\footnotetext{
${ }^{13}$ Due to a language error, what we are calling 'Occasional' here was actually called 'Eventual' in the questionnaire. Rather than perpetuate the error in this paper, we are using the term 'Occasional' but acknowledge the fact that the use of 'Eventual' in the questionnaire may have caused some confusion. Given that respondents interpreted this option in the light of the other two options in the sequence, namely 'Main task' and 'Secondary task', however, we are confident that they would have interpreted 'Eventual task' to mean one that is of lesser importance, or that is carried out less frequently, than a 'Main' or even a 'Secondary' task. Furthermore, how participants would decide if a task had enough weight to be considered 'Main', 'Secondary', or 'Eventual'/‘Occasional' was not predetermined, and the survey relied upon the perception of each respondent.

${ }^{14}$ Each 'Main task' counted 3 points; each 'Secondary task', 2 points; and each 'Occasional task', 1 point.

15 The possibility of leaving a task empty is allowed to reduce the clicks a respondent would need to choose 'N/A' for each unnecessary task.
} 
We drafted a list of seventeen criteria for the professional profile of an MT post-editor candidate so as to ask our respondents which of them their firm considers for hiring purposes (question 38 "Which of the following criteria does your firm/company apply to recruit or select a post-editor of MT?”) (cf. Appendix 2). The respondent could choose among four importance levels for each row: 'Mandatory', 'Very important', 'Important', and 'Not important'. 'Productivity (processing speed)' appears in the list of criteria as it can be explicitly asked of the freelancer by the vendor. As a hiring criterion, it is, however, crude. Nevertheless, a decision was made to ask about productivity in the sense of 'processing speed' in our questionnaire, but the authors acknowledge that high speed in itself is insufficient, and that it should be combined with quality.

One limitation of this study is the fact that the respondent may not always be aware of hiring strategies at the HR department, as we have seen in section 2.2, as they may belong to other departments. Nonetheless, the authors' experience has shown that selecting a post-editor for a project or hiring a new member of a linguistic team is hardly ever done in isolation by the HR department, and usually the project manager or the senior translator that will work with the new recruit takes part in the selection process. A list of eleven skills was drafted for question 39 ("Please rate the following MT postediting skills and competencies according to the importance you think they have for a professional post-editor") (cf. Appendix 3). The respondent could rate each element using a scale from 1 (slightly important ${ }^{16}$ ) to 5 (very important). A bubble note informed the participant that leaving a row empty would correspond to finding the skill not relevant for a professional MT post-editor.

Finally, section 5 of the survey ("Training in Machine Translation Post-Editing"), enquired about any MTPE training courses provided by the firm. If certain answers were chosen (the trainer is an in-house employee, and the respondent knows what elements the training covers), question 52 would appear: What elements does the training include? For this multiple-choice question, we provided the items shown in Appendix 4.

In the next section, the results are discussed, and future industry trends are debated.

\footnotetext{
16 The 5-point Likert scale levels ('slightly important' up to 'very important') have been decided as the list of 11 skills had been built thanks to previous literature stating to some extent the proven importance of one skill or another. Leaving a skill empty would compute as 0.
} 


\section{Analysis and Interpretation of Results}

Microsoft Excel, and especially its pivot tables feature, was used to analyze the survey data. Once the data had been prepared and the averages calculated, we looked for statistical significance in the divergence among the results using the following formula: ${ }^{17}$

$$
\text { difference } \sigma=\sqrt{p_{1}}\left(100-p_{1}\right) / n_{1}+p_{2}\left(100-p_{2}\right) / n_{2}
$$

\subsection{PE Tasks}

Questions 34 and 35 ("What workload do the following PE tasks represent for your [freelance | in-house] post-editors?") address the tasks on which post-editors spend their working time. There were 63 valid responses for this question: $40 \%$ (25) concerned the freelancers, $11 \%$ (7) only filled out the section for in-house post-editors, and 49\% (31) answered both sections.

From the data collected in these questions, we learned that the tasks most often chosen by the respondents, without considering any other variables, are (1) Revision of post-edited MT output (bilingual), (2) Quality control and text checking, (3) Proofreading of postedited output (monolingual), (4) MT output quality evaluation (error categorization...), and (5) Feedback collection on MT output quality. If we focus on the three categories provided (i.e. classifying each task as 'Main task', 'Secondary task', or 'Occasional task'), we observe that, leaving out the actual task of PE, the three Main tasks a posteditor performs more often are: (1) Revision of post-edited MT output (bilingual), (2) Quality control and text checking, and (3) Proofreading of post-edited output (monolingual). The top three Secondary tasks carried out by a post-editor are (1) MT output quality evaluation (error categorization...), (2) Feedback collection on MT output quality, and, again, (3) Quality control and text checking.

One factor that may affect the workload distribution is being an independent worker (freelance) or an in-house post-editor. It should be noted that out of the 38 LSCs which do have in-house post-editors, only one respondent states that their linguists spend their entire working day exclusively post-editing MT output. When comparing the workload of

\footnotetext{
${ }^{17}$ The formula has been extracted and tested from this website: http://x18.link/significance.
} 
in-house post-editors to the freelancers, we find two statistically significant facts. First, Quality control and text checking is most often done in-house, whereas Revision of postedited MT output (bilingual) is more often outsourced. Second, there are two other tasks that are typically "in-house tasks": Supporting users with CAT/MT tools, and Management of PEMT projects: outsourcing, etc.

The following part of the article moves on to describe in greater detail how the workload distribution varies considering the degree of expertise of the respondents and the weight ${ }^{18}$ of each task category. One of the most prominent results is the fact that the Advanced respondents assign more weight to Occasional tasks, whereas the other groups assign more weight to the Main and Secondary tasks. This can be seen in Figure 1 and it demonstrates that the MT post-editor is, or becomes in practice, a hybrid professional profile. Because of this task diversification, candidate selection and training design and implementation certainly become more complex.

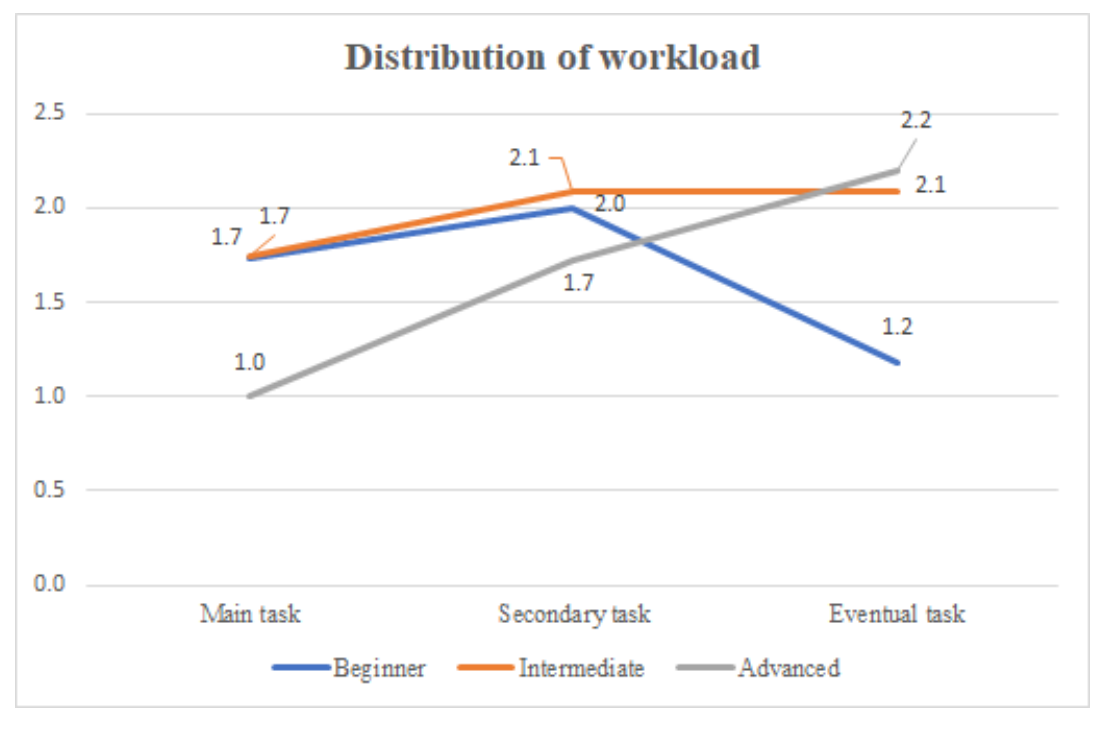

Figure 1. Distribution of workload

In Figure 1, we find one statistically significant divergence between the group Intermediate and the Advanced that should be commented on: the former shows higher numbers of Main tasks than the latter, which could be indicative of a heavier workload, in general, for the LSCs that have acquired some experience in MTPE but have not yet distributed each task to a very specific job profile.

\footnotetext{
${ }^{18}$ By computing 3 points for a Main task, 2 for a Secondary task, and 1 for an Occasional task.
} 
Figure 2 shows the divergences between each level (Beginner, Intermediate, and Advanced). We can observe that while tasks such as Quality control and text checking or Proofreading of post-edited output (monolingual) are more often chosen by the Beginner group, the Intermediate group tends to ask their post-editors to do tasks such as Terminology extraction and termbank management (which is found to be statistically significant compared to the Beginner group).

The fact that the Intermediate group requests more often the Revision of post-edited MT output (bilingual) task may result from noticing that proofreading alone is not enough to achieve the expected quality level. We could hypothesize that, with a higher level of expertise, the MT engines, source files and choice of project for using MTPE are mastered or better handled, and this could explain why the Advanced group shows more balanced levels for Proofreading of post-edited output (monolingual) and Revision of post-edited MT output (bilingual), a slightly higher result for Quality control and text checking, and a higher score for the actual task of Post-editing machine translation output.

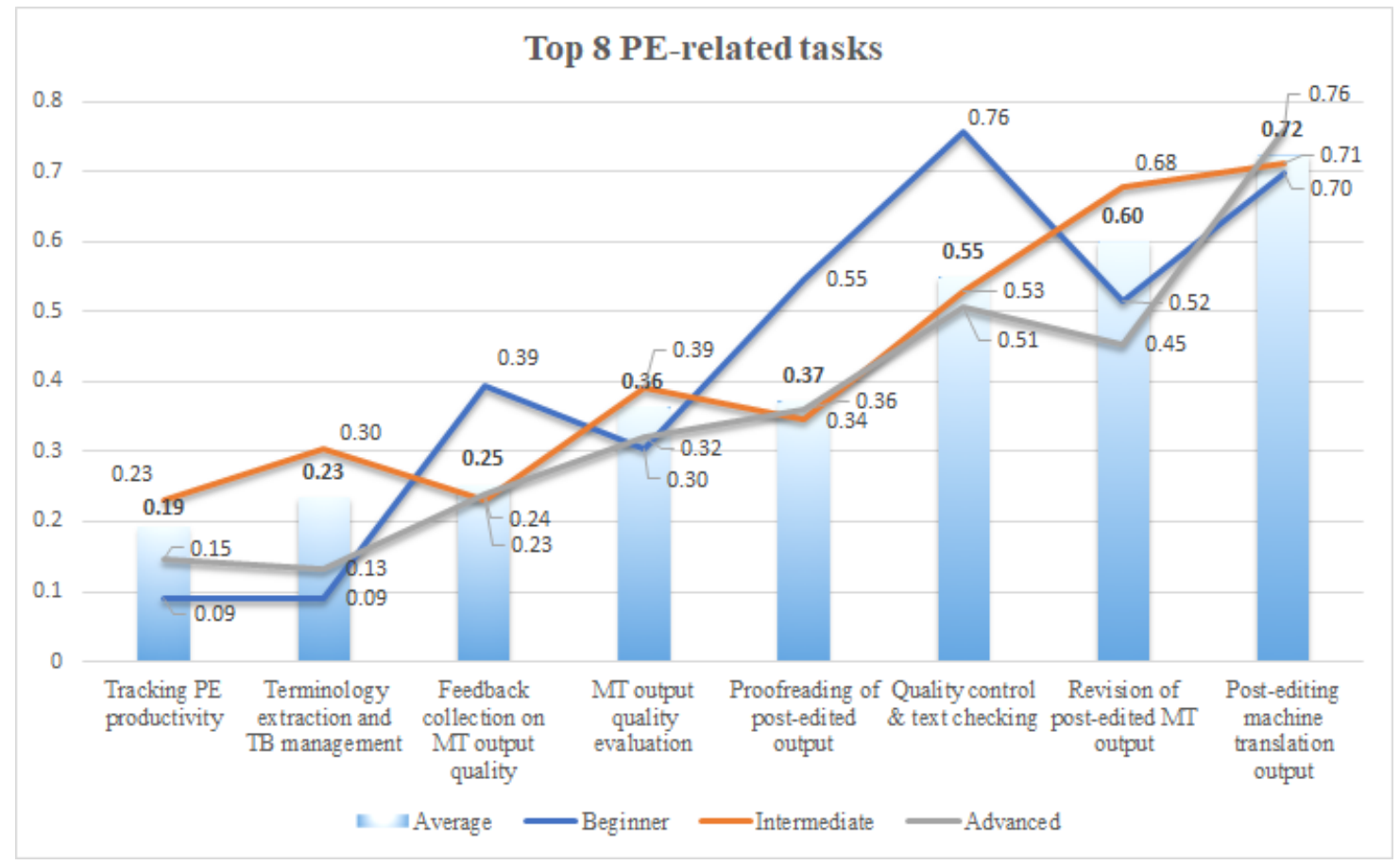

Figure 2. Top 8 PE-related tasks 


\subsection{PE Criteria}

Productivity is a dominant feature of the language and globalization market, to the extent that it becomes a defining factor for the task of PE (Absolon 2018). But is it also a steering criterion when it comes to recruiting post-editors? What elements are most valued in a PE professional from the human resources perspective? In the following paragraphs we discuss which criteria are more often valued by LSCs when selecting or hiring a post-editor. The four possible answers were assigned a numeric value for the analysis: 'Mandatory' (3 points), 'Very important' (2 points), and 'Important' (1 point). Leaving a row empty or choosing 'Not important' has the value of 0 .

The top 10 criteria that the respondents of our survey consider when hiring a post-editor, according to question 38 ("Which of the following criteria does your firm/company apply to recruit or select a post-editor of MT?”) are, in order of frequency: (1) Revision and proofreading skills, (2) Subject field knowledge or specialization, (3) CAT tool(s) knowledge, (4) University degree in Translation or related studies, (5) Productivity (processing speed), (6) Quality Assurance (QA) checking skills, (7) Previous experience in MTPE, (8) Terminology management and information mining skills, (9) Specific locale (sublanguage), and (10) MT system knowledge.

A more detailed account of how the three expertise levels may affect the choice of one criterion over another when selecting a post-editor is given in the following lines and shown in Figure 3. The fact that a candidate would say s/he has Revision and proofreading skills is a steering criterion for the three groups of respondents. Having CAT tool(s) knowledge is highly valued by Beginner and Intermediate LSCs, whereas holding a University degree in Translation or related studies is even more important for the Beginner group. Indeed, the degree seems less important to the Advanced group, and even less to the Intermediate LSCs. This could be due either to a better and more thorough selection process (if an LSC is able to assess by itself other features, then having a degree may become superfluous) or a high and urgent demand for a very specific profile (with less common languages and very narrow subject fields, a degree may become too difficult a criterion to fulfill). 


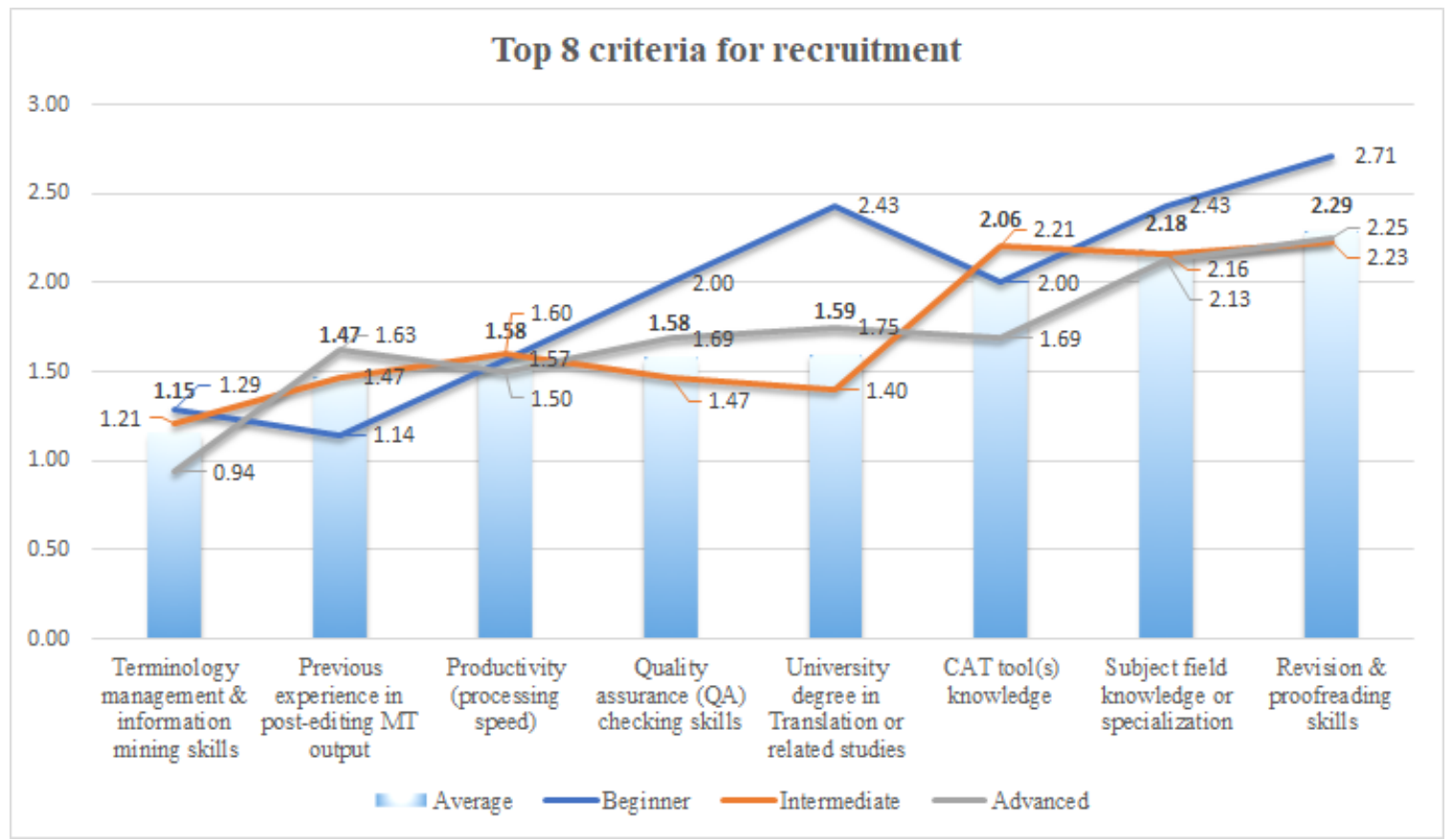

Figure 3. Top 8 criteria for recruitment

To conclude with the criteria for hiring post-editors, we should highlight that only the Specific locale (variant, sublanguage), which on average holds the ninth position, shows a statistically significant difference between the Beginner and the other two groups: it would seem that the former do not take it into account as much as the Intermediate and Advanced groups do. For the rest, the divergences between the three groups are not statistically significant.

\subsection{PE Skills}

Understanding the complexity of the post-editor skill set is vitally important if we are to improve the reputation of MTPE among professionals and build a sound basis for MTPE training courses. The PE skills considered to be the most important for a professional post-editor, according to question 39 of our survey (Please rate the following MT postediting skills and competencies according to the importance you think they have for a professional post-editor. $1=$ slightly important $\mid 5=$ very important) are the capacity 
${ }^{19}$ (1) to post-edit up to human quality (full PE); (2) to post-edit according to PE guidelines; (3) to decide when to work on a segment or discard it; ${ }^{20}$ (4) to identify MT output errors; (5) to post-edit to a good enough quality (light PE); and (6) to apply the right correction strategy (which is closely related to first identifying the error, of course). The fact that the person who post-edits MT output must be capable of achieving "human quality" suggests that the translation competency model remains essential; it is the foundation on which we should build to create the MTPE skill set.

When we look at how expertise might affect valuing one skill more than another, we notice that more experienced providers find less important the Capacity to post-edit to a good enough quality (light PE). Overall, as can be seen in Figure 4, we observe a very high level of inter-rater agreement across the three levels of expertise regarding the skill set necessary for a post-editor. It is worth highlighting that the Beginner group of participants appreciate the Capacity to post-edit up to 'good enough' quality, and the Capacity to identify MT output errors more than the two other groups, which suggests that the first MTPE projects and initial experiences in the field may come with a high amount of both over-editing and under-editing.

\footnotetext{
${ }^{19}$ The word "capacity" is defined by Merriam-Webster as "individual's mental or physical ability: aptitude, skill." It has been used in the questionnaire's answer as a synonym of "skill" for the purposes of clearly phrasing the concepts for the respondents.

${ }^{20}$ The skills marked (2) and (3) actually tied in second place.
} 
Top 8 PE skills

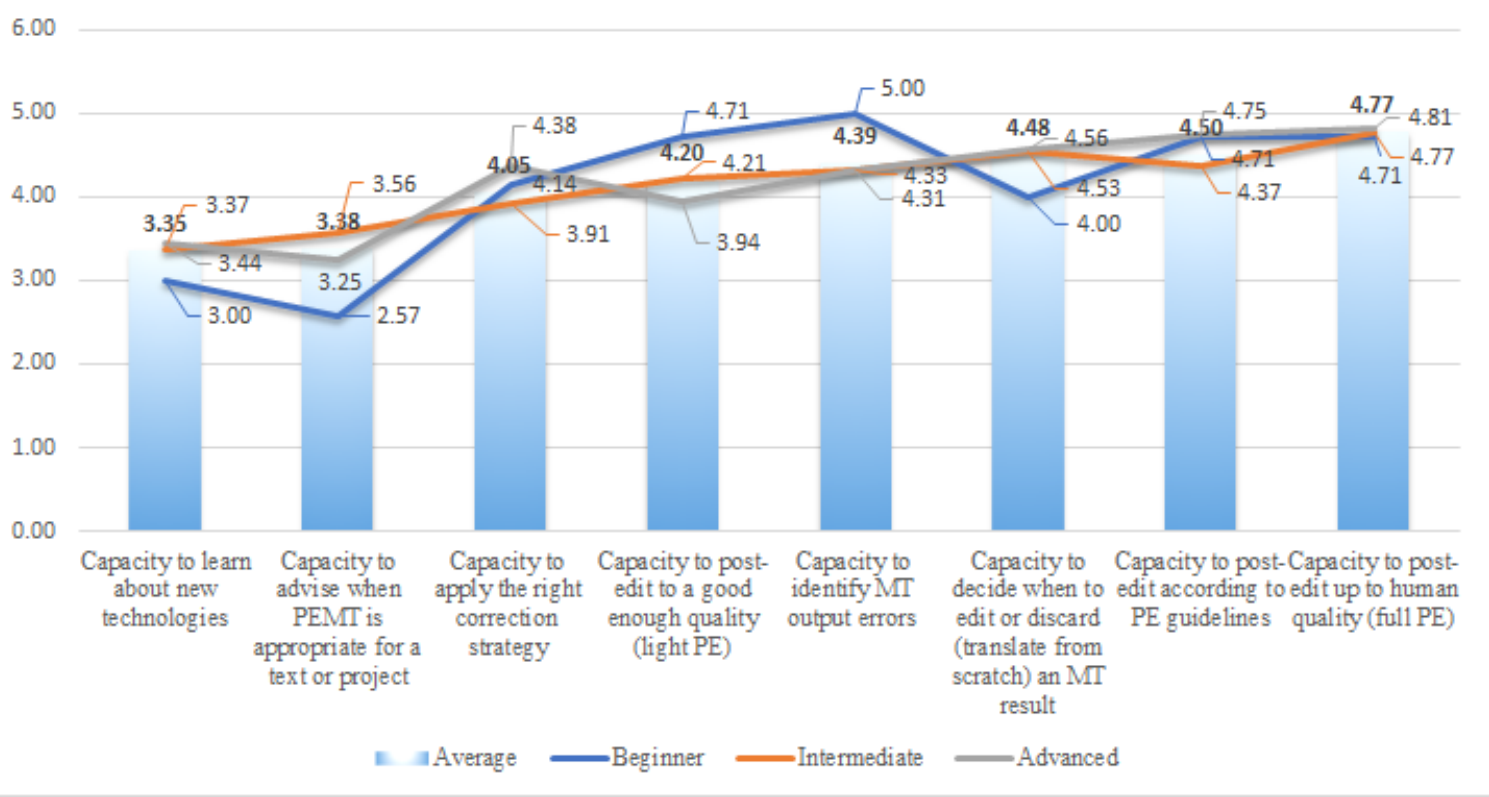

Figure 4. Top 8 PE skills

One noticeable difference that has been found to be statistically significant is the comparison between the skills and the tasks: our respondents give high scores to the Capacity to pre-edit a source text according to CL, whereas the task Pre-editing the source text is not as important, nor is it considered as important from a hiring perspective.

\subsection{MTPE Training Content}

Several studies have documented training courses on MTPE (cf. section 1). However, out of the 66 respondents to our survey, only 22 have organized a training course on MTPE. $59 \%$ of these 22 respondents have done so at least once in the past and the other $41 \%$ organize MTPE training courses regularly. We asked them who does the training and 18 respondents replied that it is provided by in-house staff. For these respondents, question 52 appeared: What elements does the training include?

The elements that current training courses cover most often are shown in Figure 5 and enumerated in the following lines: (1) PE levels: light and full post-editing; (2) PE guidelines: exhaustive list and examples in the relevant language pair; ${ }^{21}$ (3) PE attitude: decide when to discard and translate from scratch; (4) MT systems: rule-based, example-

\footnotetext{
${ }^{21}$ Training content (2) and (3) actually hold the same position, as can be seen in Figure 5.
} 
based, statistical, hybrid or neural; (5) PE risks: under-editing, over-editing and pseudoediting; (6) Integration between CAT tool and MT system; (7) PE techniques and strategies (shift, replacement, addition, deletion); ${ }^{22}$ and (8) Practical PE exercises in the relevant language pair.

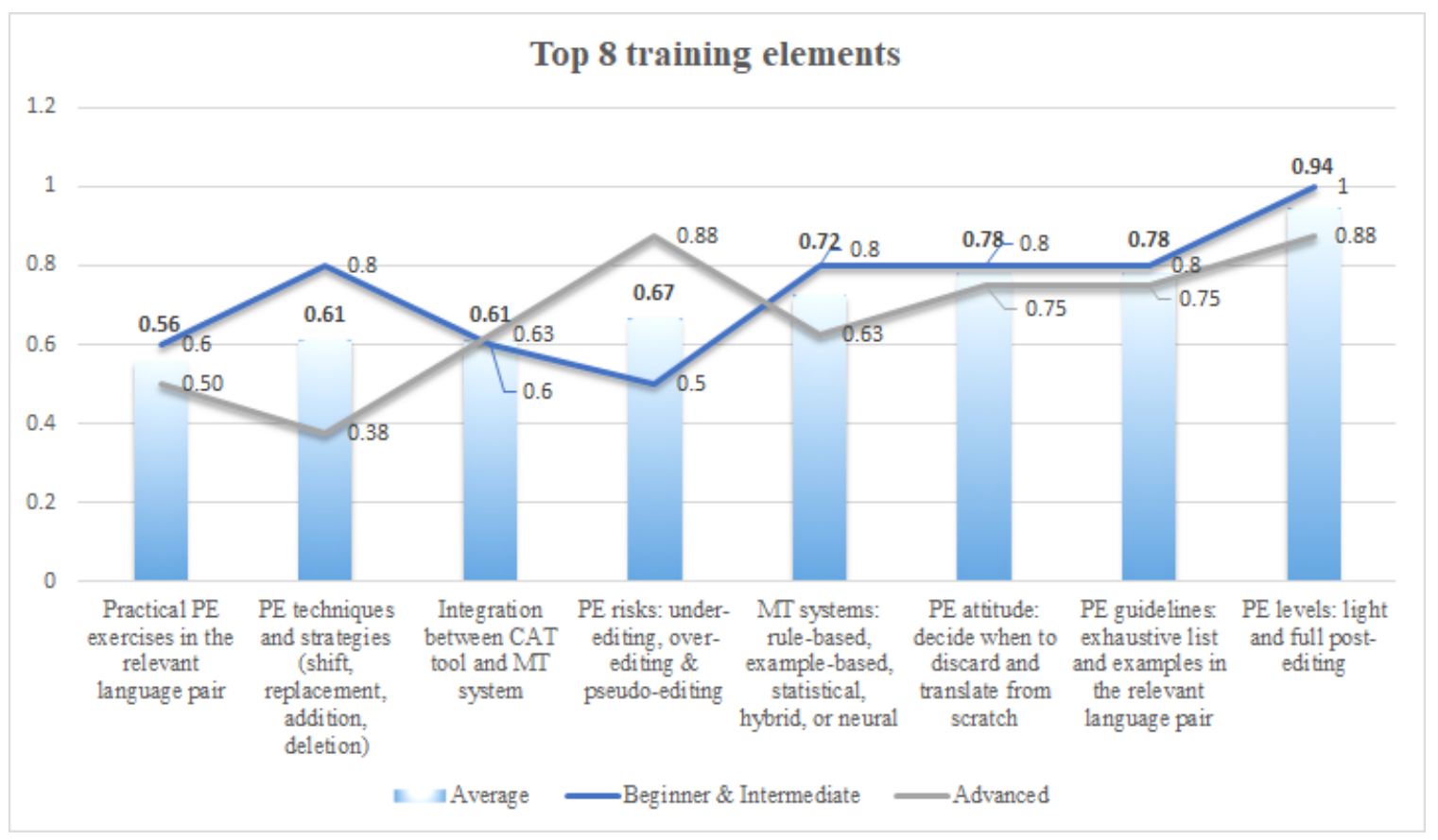

Figure 5. Top 8 training elements

For the purpose of the analysis, we have combined the Beginner and the Intermediate groups, since the first one only had three respondents who answered this question. In Figure 5, we can observe how important the PE levels are for all the respondents. The fact that it is necessary to "teach" that quality levels exist and that not all MTPE deliveries must reach the level of perfection that is usually aimed at in any translation course constitutes one differentiating element between the translator and the post-editor profile.

\section{Conclusion}

As the globalization industry is constantly evolving, we must not define a fixed list of profiles, guidelines, skills, or exercises, but keep adapting our views, resources and

\footnotetext{
${ }^{22}$ Training content (6) and (7) hold the same position, as can be seen in Figure 5.
} 
methods in the best way possible. It is hoped that our conclusions will help several stakeholders (LSCs, language professionals, firms, and trainers alike) to adjust their strategies in order to clear some of the bad reputation MTPE has had among professionals in the past years (Sakamoto 2019).

Having Revision of post-edited MT output (bilingual), Quality control and text checking, and Proofreading of post-edited output (monolingual) as the top three PE-related tasks is perfectly in line with training translators to light and full PE levels. Obviously, this assumes that translation competence has already been acquired. The correspondence between PE tasks and training content can even be extended to recruiting criteria. Indeed, Figure 3 showed us how, from the human resources point of view, the post-editor profile is very similar if not coincident with the translator profile. If translation (or translator) competence is not fully acquired - and, in particular, if thematic competence and revision skills are not mastered-we cannot expect a candidate post-editor to provide good results. While the industry seems to have a very practical way of assessing if a candidate is a good fit for a job (subject field and CAT tools knowledge were the second- and thirdmost valued criteria), MTPE training courses are, for now, more focused on PE skills proper, such as deciding when to edit or discard a segment. However, we can imagine how the third-most trained element (PE guidelines: exhaustive list and examples in the relevant language pair) may also include 'relevant domain' or 'relevant text-type' examples. Regardless of what degree of specialization is included in MTPE plans at LSCs, it is a positive result to see how they succeed at connecting their perception of PE skill sets to their training programs, as we discuss in the following paragraphs.

The top two skills, as described in section 4, are the Capacity to post-edit up to human quality (full PE), and the Capacity to post-edit according to guidelines. They match with the top three training elements and they both demonstrate that, not only is translation competence a sine qua non condition for the post-editor profile, but that translator competence is also fundamental, as respect for PE guidelines is comparable to respect for the well-known translation assignment, the main reference in any translation job and an important training element covered throughout Translation Studies. Although we should not stray too far from Translation Studies, MTPE does differ in practice from translation, as it involves an added layer of complexity (Nitzke et al. 2019; Plaza Lara 2019) that 
calls for specialized training. For instance, in Figure 4 we saw that the Capacity to decide when to edit or discard an MT result (and thus translate from scratch) and the Capacity to identify MT output errors hold the third and fourth positions. This corresponds perfectly with LSCs training their professionals on PE attitude: decide when to discard and translate from scratch (third position), MT systems: rule-based, example-based, statistical, hybrid or neural (fourth position), and PE risks: under-editing, over-editing and pseudo-editing (fifth position).

With this survey-based research we have found that Intermediate LSCs ask a high number of 'Main' tasks from their post-editors, whereas Advanced LSCs tend to have many more 'Occasional' tasks, as seen in Figure 1. This, together with the discussion in the paragraphs above, helps answer RQ1: the MT post-editor is indeed a hybrid and transdisciplinary profile, for many differing tasks and skills are required from the MTPE professional. Although the MTPE expertise level may shed light on some particular trends, few statistically significant results have shown divergences among the three groups. Thus, we cannot state that this expertise level is indicative of best practices in the MTPE industry. To give a satisfactory answer to RQ2 we would need to survey a bigger population.

As was pointed out in section 1 and confirmed by the results regarding PE-related tasks, recruitment criteria and skills, cognitive load is an important factor for post-editors of MT. Hence, to allow the professionals to proceduralize a certain number of translation sub-tasks and, thus, release cognitive capacity for more demanding tasks, we must establish which skills need to be practiced in parallel and in what sequential order (Göpferich 2013).

We thus suggest that the top $8 \mathrm{PE}$ skills presented in this article should be grouped into a more comprehensive competency model (as described by the EMT Board [2017], for instance), and that the top 8 training elements should be rethought in a manner so as to be introduced in translation curricula in parallel or just after the thematic knowledge and the revision courses begin, i.e., not before the second cycle at the undergraduate stage and probably best at the postgraduate level (O’Brien 2002; Plaza Lara 2019). We should also build upon the work by Sánchez-Gijón (2016) and consider the inclusion of “paraprofessionals" (Pym 2011), "paralinguists” (Van Ess-Dykema et al. 2010), or 
"language consultants" (Nitzke et al. 2019) in her overview of potential PE-related profiles.

One important limitation of our survey-based research is the number of respondents to the questionnaire. 66 submissions is a small number compared to the 271 responses received from language companies at the 2019 edition of the Language Industry Survey. However, that survey also states that "less than $20 \%$ of the translation companies report that they are frequently using machine translation" (EUATC et al. 2019).

In future work we plan to identify the existing gaps between the survey data presented in this article, and the data collected via a second questionnaire addressed to individual (freelance or in-house) language professionals who post-edit MT output as part of their job. We will then compare current training programs at universities to the data collected using these two surveys, which will enable us to decide to what extent the needs of the PE students and professionals are being met. This should allow for an improvement of PE training courses, and even for the adjustment of some processes and workflows by industry stakeholders.

\section{Acknowledgments}

The authors would like to thank the 66 respondents of the questionnaire, who made this research possible.

We also send our gratitude to the organizations, universities, companies, groups or journals that contributed to disseminating the questionnaire: the European Union of Associations of Translation Companies (EUATC), Association of Language Companies (ALC), European Language Resource Coordination (ELRC), Translation Automation User Society (TAUS), European Association of Machine translation (EAMT), Association suisse des traducteurs, terminologues et interprètes (ASTTI), Bundesverband der Dolmetscher und Übersetzer (BDÜ), Association professionnelle des métiers de la traduction (Aprotrad), the European Legal Interpreters and Translators Association (EULITA), Association d'interprètes et de traducteurs (AIT), Euskal Itzultzaile, Zuzentzaile eta Interpreteen Elkartea (EIZIE), Slator, Universitas, Multilingual, Systran, Linguist Lounge, Learned Publishing, World Translation Jobs, the World Association of Newspapers and News Publishers (WANIFRA), and Institut de Management et de Communication Interculturels (ISIT). 
We really appreciate the help provided by the English team at Datawords, and we would like to thank especially May Babic Bell and John Ryan-Mills for their involvement in proofreading our article.

\section{References}

Absolon, Jakub. 2018. The Need for Competency-based Selection and Training of Post-editors. Nitra: ASAP-translation.com.

Absolon, Jakub. n.d. English-Slovak MTPE Course. Nitra: ASAP-translation.com. Accessed 14 July 2019 , http://mtposteditors.com/tests/test_EN_SK_01.html.

Allen, Jeffrey. 2003. "Post-Editing." In Computers and Translation: A Translator's Guide, edited by Harold Somers. Benjamins Translation Library, 35. Amsterdam: John Benjamins. DOI 10.1075/btl.35.

American Translators Association. 2018. ATA Position Paper on Machine Translation. Accessed 20 July 2019, http://x18.link/ATA2018.

Austermühl, Frank. 2013. "Future (and Not-So-Future) Trends in the Teaching of Translation Technology". Tradumàtica: Tecnologies de la Traducció, 11: 326-337. DOI 10.5565/rev/tradumatica.46.

Blagodarna, Olena. 2018. Enhancement of Post-Editing Performance: Introducing Machine Translation Post-Editing in Translator Training. PhD dissertation, Universitat Autònoma de Barcelona.

Blanco Caraco, José Luis. 2012. “Calculadoras de significancia estadística en resultados de encuestas [Calculators of statistical significance in survey results].” In Ciencia explicada. Accessed 19 July 2019 , http://xl8.link/significance.

BS ISO (British Standards Document). 2015. Translation Services. Requirements for Translation Services. BS EN ISO 17100:2015+A1:2017, DOI 10.3403/30246895U.

BS ISO (British Standards Document). 2017. Translation services. Post-editing of machine translation output. Requirements. BS ISO 18587:2017, DOI 10.3403/30279909U.

Bundgaard, Kristine, and Tina Paulsen Christensen. 2019. "Is the Concordance Feature the New Black? A Workplace Study of Translators' Interaction with Translation Resources while Post-Editing TM and MT Matches." In The Journal of Specialised Translation. 31: 14-37. Accessed 14 July 2019, http://www.jostrans.org/issue31/art_bundgaard.php. 
Calvo Encinas, Elisa. 2009. Análisis curricular de los estudios de traducción e interpretación en España: experiencia curricular del estudiantado [Analysis of the Curricula of Translation and Interpreting Studies in Spain: Curricular Experience of the Students]. PhD Thesis, Universidad de Granada.

Castilho, Sheila, Joss Moorkens, Federico Gaspari, Iacer Calixto, John Tinsley, and Andy Way. 2017. "Is Neural Machine Translation the New State of the Art?" The Prague Bulletin of Mathematical Linguistics. 108 (1): 109-120. DOI 10.1515/pralin-2017-0013.

Cid-Leal, Pilar, María-Carmen Espín-García, and Marisa Presas. 2019. “Traducción automática y posedición: perfiles y competencias en los programas de formación de traductores [Machine translation and post-editing: profiles and competencies in translator training programmes]" In MonTI: Because Something should Change: Present and Future Training of Translators and Interpreters. 11: 187-214.

Daems, Joke, Michael Carl, Sonia Vandepitte, Robert Hartsuiker, and Lieve Macken. 2016. “The Effectiveness of Consulting External Resources During Translation and Post-Editing of General Text Types." New Frontiers in Translation Studies. 111-133. DOI 10.1007/978-3-319-20358-4_6.

DigiLing n.d. Post-Editing Machine Translation. Online training course. Accessed 14 July 2019, https://learn.digiling.eu/.

do Carmo, Félix. 2017. Post-editing: A Theoretical and Practical Challenge for Translation Studies and Machine Learning. PhD dissertation, Universidad do Porto.

Doherty, Stephen, and Dorothy Kenny. 2014. "The Design and Evaluation of a Statistical Machine Translation Syllabus for Translation Students." The Interpreter and Translator Trainer 8 (2): 295-315.

DOI 10.1080/1750399x.2014.937571.

Doherty, Stephen, and Federico Gaspari. 2013. "Effective Post-Editing in Human and Machine Translation Workflows: Critical Knowledge and Techniques." Presentation given at the QTLaunchPad Post-Editing Webinar. Accessed 20 June 2019, http://x18.link/QT21_2013.

Egdom, Gys Van, Lucas Nunes Vieira, and Jakub Absolon. 2018. “Towards Testing Post-Editing Performance: A Futureproof Diagnostic Tool.” Tradumàtica. Tecnologies de la Traducció, 16: 114-124. DOI 10.5565/rev/tradumatica.211.

EMT Board. 2017. Master Européen en Traduction (EMT) Expliqué. Référentiel des Compétences EMT. [European Master's in Translation_EMT Competence Framework]. Accessed 6 June 2019, https://ec.europa.eu/info/sites/info/files/emt_competence_fwk_2017_fr_web.pdf. 
EUATC, GALA, FIT, elia, EMT and LIND-Web. 2018 Language Industry Survey—Expectations and Concerns of the European Language Industry. Accessed 9 June 2019, http://x18.link/LIS18.

EUATC, GALA, FIT, elia, EMT and LIND-Web. 2019 Language Industry Survey-Expectations and Concerns of the European Language Industry. Accessed 9 June 2019, http://x18.link/LIS19.

Forcada, Mikel L. 2017. “Making Sense of Neural Machine Translation.” Translation Spaces 6 (2): 291309. DOI 10.1075/ts.6.2.06for.

Gaspari, Federico, Hala Almaghout, and Stephen Doherty. 2015. "A Survey of Machine Translation Competences: Insights for Translation Technology Educators and Practitioners." Perspectives 23 Studies in Translatology 23 (3): 333-358. DOI 10.1080/0907676X.2014.979842.

Gile, Daniel. 2006. “Do Respondents to Surveys Tell the Truth?”. European Society for Translation Studies. Accessed 15 July 2019, http://xl8.link/EST_Gile.

Göpferich, Susanne. 2013. "Translation Competence. Explaining Development and Stagnation from a Dynamic Systems Perspective.” Target 25 (1): 63-78. DOI 10.1075/target.25.1.06goe.

Green, Spence, Jeffrey Heer, and Christopher D. Manning. 2013. "The Efficacy of Human Post-Editing for Language Translation." In ACM Factors in Computing Systems, Paris, France. DOI $10.1145 / 2470654.2470718$.

Guerberof, Ana, and Joss Moorkens. 2019. "Machine Translation and Post-Editing Training as Part of a Master's Programme." The Journal of Specialised Translation. 31: 217-238. Accessed 14 July 2019, http://x18.link/31guerberof.

Guerberof, Ana, Heidi Depraetere, and Sharon O’Brien. 2012. "What We Know and What We Would Like to Know About Post-Editing.” Tradumàtica: tecnologies de la traducció, (10): 211-218.

DOI 10.5565/rev/tradumatica.28.

Guerberof, Ana. 2013. "What do Professional Translators Think About Post-Editing?” The Journal of Specialised Translation. 19: 75-95. Accessed 20 November 2018, https://www.jostrans.org/issue19/art_guerberof.pdf.

Guerrero, Lucía. 2017. LSP Perspective: Applying the Human Touch to MT, Qualitative Feedback in MT evaluation (Part 1). Accessed 9 June 2019, http://x18.link/CPSL.

Henderson, Stephen. 2016. The Top 100 Language Service Providers: 2016. Common Sense Advisory Research. Accessed 20 June 2019, http://x18.link/CSA2016. 
Hyperion Ltd. n.d. EU Associations. Hyperion Ltd. Accessed 30 November 2018, http://x18.link/hyperion.

Jia, Yanfang, Michael Carl, and Xiangling Wang. 2019. "How does the Post-Editing of Neural Machine Translation Compare with From-Scratch Translation? A Product and Process Study." The Journal of Specialised Translation. 31: 60-86. Accessed 30 November 2018, http://www.jostrans.org/issue31/art_jia.php.

Joscelyne, Andrew, and Colin Brace. 2010. Postediting in Practice. A TAUS Report. Accessed 20 June 2019, http://x18.link/TAUS2010.

KantanMT. n.d. Training MT Post-Editors. Accessed 20 June 2019, http://x18.link/KMT.

Koponen, Maarit. 2015. "How to Teach Machine Translation Post-Editing? Experiences from a PostEditing Course." Proceedings of 4th Workshop on Post-Editing Technology and Practice. Accessed 20 June 2019, http://xl8.link/Koponen2015.

Koponen, Maarit. 2018. "Learning to Post-Edit: An Analysis of Post-Editing Quality and Processes of Translation Students.” International Association for Translation and Intercultural Studies (IATIS) $6^{\text {th }}$ International Conference. DOI 10.13140/RG.2.2.24675.04648

Krings, Hans P., and Geoffrey S. Koby (eds). 2001. Repairing Texts: Empirical Investigations of Machine Translation Post-Editing Processes. Kent, Ohio: The Kent State University Press.

Marheinecke, Katrin. 2016. "Post-editing Machine Translation. What does it take?" Translating Europe Forum 2016. Accessed 20 June 2019, http://xl8.link/marheinecke.

Mesa-Lao, Bartolomé. 2014. "Speech-Enabled Computer-Aided Translation: A Satisfaction Survey with Post-Editor Trainees." Proceedings of the EACL 2014 Workshop on Humans and Computer-Assisted Translation. DOI 10.3115/v1/w14-0315.

Moorkens, Joss, and Sharon O’Brien. 2017. “Assessing User Interface Needs of Post-Editors of Machine Translation." In Human Issues in Translation Technology, edited by Dorothy Kenny, 109-130. London and New York: Routledge. DOI 10.4324/9781315648934.

Nitzke, Jean, Silvia Hansen-Schirra, and Carmen Canfora. 2019. "Risk Management and Post-Editing Competence." The Journal of Specialised Translation. 31: 239-259. Accessed 20 June 2019, http://xl8.link/Nitzke.

O’Brien, Sharon, Laura Winther Balling, Michael Carl, Michel Simard, and Lucia Specia (eds). 2014. PostEditing of Machine Translation: Processes and Applications. Cambridge Scholars Publishing: United Kingdom. 
O’Brien, Sharon. 2002. “Teaching Post-editing: A Proposal for Course Content.” In Proceedings of the $6^{\text {th }}$ European Association for Machine Translation (EAMT) Workshop, Teaching Machine Translation, 99-

106. Accessed 20 June 2019, http://x18.link/OBrien2002.

Oncins de Frutos, Margarita. 2008. "NTP 283: Encuestas: metodología para su utilización [Surveys: Methodology for Implementation]." Accessed 20 June 2019, http://x18.link/surveys.

PACTE. 2014. "First Results of PACTE Group's Experimental Research on Translation Competence Acquisition: The Acquisition of Declarative Knowledge of Translation.” In MonTI Special Issue. Minding translation, edited by R. M. Martín, 85-115. DOI 10.6035/MonTI.2014.ne1.2.

Plaza Lara, Cristina. 2019. "SWOT Analysis of the Inclusion of Machine Translation and Post-Editing in the Master's Degrees Offered in the EMT Network." The Journal of Specialised Translation. 31: 260-280. Accessed 30 November 2018, http://www.jostrans.org/issue31/art_plaza.php.

Popović, Maja, Arle Lommel, Aljoscha Burchardt, Eleftherios Avramidis, and Hans Uszkoreit. 2014. "Relations between Different Types of Post-Editing Operations, Cognitive Effort and Temporal Effort." In Proceedings of the 17th Conference of the European Association for Machine Translation (EAMT14), 191-198. Accessed 20 June 2019, http://x18.link/Popovic.

Pym, Anthony. 2009. Translator training. Tinet. Accessed 20 June 2019, http://x18.link/Pym2009.

Pym, Anthony. 2011. "What Technology Does to Translating." The International Journal for Translation and Interpreting Research. Accessed 20 June 2019, http://x18.link/Pym2011.

Pym, Anthony. 2013. “Translation Skill-Sets in a Machine-Translation Age.” Meta 58 (3): 487.

DOI 10.7202/1025047ar.

Rico Pérez, Celia, and Enrique Torrejón. 2012. "Skills and Profile of the New Role of the Translator as MT Post-editor." Tradumàtica: tecnologies de la traducció, 166-178. DOI 10.5565/rev/tradumatica.18

Rico Pérez, Celia, and Pedro L. Díez Orzas. 2013. "EDI-TA: Post-Editing Methodology for Machine Translation." Multilingualweb-LT Deliverable 4.1.4. Annex I. Accessed 20 June 2019, http://x18.link/Rico2013a.

Rico Pérez, Celia, and Pedro L. Díez Orzas. 2013. "Training Methodology for Machine Translation Postediting." Multilingualweb-LT Deliverable 4.1.4. Annex II. Accessed 15 July 2019, http://x18.link/Rico2013b.

Rossetti, Alessandra, and Federico Gaspari. 2017. "Modelling the Analysis of Translation Memory Use and Post-Editing of Raw Machine Translation Output: A Pilot Study of Trainee Translators' Perceptions.” In 
Empirical Modelling of Translation and Interpreting, 41-67. Berlin: Language Science Press.

DOI 10.5281/zenodo.1090952.

Sakamoto, Akiko. 2019. "Why Do Many Translators Resist Post-Editing? A Sociological Analysis Using Bourdieu's Concepts Description.” The Journal of Specialised Translation. 31: 201-216. Accessed 20 June 2019, http://x18.link/Sakamoto.

Sánchez-Gijón, Pilar. 2016. "Post-Editing: Towards a Competency-Based Definition of the Profile and a Multidimensional Description of the Phenomenon.” In Sendebar 27: 151-162. Universidad de Granada. Accessed 30 November 2018, http://revistaseug.ugr.es/index.php/sendebar/article/view/4016.

SDL. 2016. SDL Research Study 2016: Translation Technology Insights. 23. Accessed 30 November 2018, https://www.sdl.com/download/tti16-productivity/109572/.

SDL. n.d. Post-édition de traduction automatique [Post-editing of Machine Translation]. Online training course: https://www.sdltrados.com/fr/learning/certification/.

Sycz-Opoń, Joanna, and Ksenia Gałuskina. 2017. "Machine Translation in the Hands of Trainee Translators-An Empirical Study.” Studies in Logic, Grammar and Rhetoric 49 (1): 195-212. DOI 10.1515/slgr-2017-0012.

Tatsumi, Midori. 2010. Post-Editing Machine Translated Text in A Commercial Setting: Observation and Statistical Analysis. PhD Thesis. Dublin City University. Accessed 14 July 2019, http://doras.dcu.ie/16062/.

Temizöz, Özlem. 2016. "Postediting Machine Translation Output: Subject-Matter Experts Versus Professional Translators.” Perspectives 24 (4): 646-665. DOI 10.1080/0907676x.2015.1119862.

Torrejón, Enrique, and Celia Rico. 2002. "Controlled Translation: A New Teaching Scenario Tailor-Made for the Translation Industry." Proceedings of 6th EAMT Workshop Teaching Machine Translation, 107116. Manchester, UK. Accessed 30 November 2018, http://mt-archive.info/EAMT-2002-Torrejon.pdf.

Tradumàtica Research Group. n.d. POST-IT: Equipo de investigación [POST-IT: Investigating Team]. Accessed 20 June 2019, http://x18.link/post-it.

van deer Meer, Jaap, and Achim Ruopp. 2014. Machine Translation Market Report 2014. Accessed 20 June 2019, http://x18.link/TAUS-MT2014.

van der Meer, Anne-Maj. 2015. Post-editing Course. Online training course. Accessed 14 July 2019, https://www.taus.net/academy/taus-post-editing-course. 
Van Ess-Dykema, Carol, Jocelyn Phillips, Florence Reeder, and Laurie Gerber. 2010. "Paralinguist Assessment Decision Factors for Machine Translation Output: A Case Study.” In AMTA 2010 -9th Conference of the Association for Machine Translation in the Americas. Accessed 14 July 2019, http://mtarchive.info/AMTA-2010-VanEss-Dykema.pdf.

Vasconcellos, Muriel. 1986. "Post-Editing On-Screen: Machine Translation from Spanish into English.” In Proceedings of Translating and The Computer 8, edited by Catriona Picken. Accessed 20 June 2019, http://x18.link/1986.

Vehovar, Vasja, Katja Lozar Manfreda, Jernej Berzelak, Gregor Čehovin, and Katja Zrim. 2019. WebSM. Web Survey Methodology. Faculty of Social Sciences, University of Ljubljana. Accessed 20 June 2019, http://xl8.link/web.

Vieira, Lucas Nunes, and Elisa Alonso. 2018. The Use of Machine Translation in Human Translation Workflows: Practices, Perceptions and Knowledge Exchange. University of Bristol and Universidad Pablo de Olavide. Accessed 30 November 2018, https://www.researchgate.net/publication/325114193.

Vintar, Špela, Ondřej Matuška, Jure Škerl, Petra Bago, Dragos Ciobanu, Vaclav Cvrček, Oliver Čulo, Miloš Jakubiček, Nives Mikelić Preradović, Jean Nitzke, Alina Secara, Zdenek Žabokrtsky. 2017. “Labour Market Needs Survey and the DigiLing Model Curriculum." In Project DigiLing: TransEuropean eLearning Hub for Digital Linguistics. Accessed 20 June 2019, http://x18.link/DigiLing.

Zaretskaya, Ana. 2017. "Machine Translation Post-Editing at TransPerfect—the 'Human' Side of the Process." Tradumàtica. Tecnologies de la Traducció (15): 116. DOI 10.5565/rev/tradumatica.201. 


\section{Appendix 1}

34. What workload do the following PE tasks represent for your in-house post-editors?

35. What workload do the following PE tasks represent for your freelance post-editors?

\begin{tabular}{|l|l|l|l|l|}
\hline & $\begin{array}{l}\text { Main } \\
\text { task }\end{array}$ & $\begin{array}{l}\text { Secondary } \\
\text { task }\end{array}$ & $\begin{array}{l}\text { Occasional } \\
\text { task }\end{array}$ & $\begin{array}{l}\text { A } \\
\text { A }\end{array}$ \\
\hline Customization/Tuning of MT engines & & & & \\
\hline Feedback collection on MT output quality for solution engineers & & & & \\
\hline Management of MTPE projects: outsourcing, etc. & & & & \\
\hline $\begin{array}{l}\text { Material preparation for MT engine training (building corpora, } \\
\text { alignment, cleaning TM...) }\end{array}$ & & & & \\
\hline MT output quality evaluation (error categorization...) & & & & \\
\hline PE guidelines design & & & & \\
\hline Post-editing machine translation output & & & & \\
\hline Pre-editing the source text & & & & \\
\hline Proofreading of post-edited output (monolingual) & & & & \\
\hline Quality control \& text checking & & & & \\
\hline Revision of post-edited MT output (bilingual) & & & & \\
\hline Support users with CAT/MT tools & & & & \\
\hline Terminology extraction and TB management & & & \\
\hline Tracking PE productivity & & & \\
\hline
\end{tabular}

\section{Appendix 2}

38. Which of the following criteria does your firm/company apply to recruit or select a post-editor of $M T$ ?

\begin{tabular}{|l|l|l|l|l|}
\hline & $\begin{array}{l}\text { Mandator } \\
\mathrm{y}\end{array}$ & $\begin{array}{l}\text { Very } \\
\text { important }\end{array}$ & $\begin{array}{l}\text { Importan } \\
\mathrm{t}\end{array}$ & $\begin{array}{l}\text { Not } \\
\text { important }\end{array}$ \\
\hline Capacity to post-edit into both directions & & & & \\
\hline CAT tool(s) knowledge & & & & \\
\hline $\begin{array}{l}\text { Certification in PE by a professional association (ProZ, } \\
\text { TAUS, etc.) }\end{array}$ & & & & \\
\hline Experience in project management & & & & \\
\hline MT system knowledge & & & & \\
\hline Pre-editing or controlled language (CL) skills & & & & \\
\hline
\end{tabular}




\begin{tabular}{|l|l|l|l|l|} 
Previous experience in post-editing MT output & & & \\
\hline Productivity (processing speed) & & & & \\
\hline Quality assurance (QA) checking skills & & & & \\
\hline Revision \& proofreading skills & & & & \\
\hline $\begin{array}{l}\text { Skills using automatic speech recognition (ASR) or } \\
\text { touch-screen technology }\end{array}$ & & & & \\
\hline Specific locale (variant, sublanguage) & & & & \\
\hline Subject field knowledge or specialization & & & & \\
\hline Technical skills: macros, xliff, tmx, Java, RegEx... & & & & \\
\hline Terminology management \& information mining skills & & & & \\
\hline $\begin{array}{l}\text { Translation Quality Assessment (TQA) skills (scores, } \\
\text { metrics, evaluation, etc.) }\end{array}$ & & & & \\
\hline University degree in Translation or related studies & & & & \\
\hline
\end{tabular}

\section{Appendix 3}

39. Please rate the following MT post-editing skills and competencies according to the importance you think they have for a professional post-editor. 1 (slightly important) to 5 (very important).

\begin{tabular}{|c|c|c|c|c|}
\hline \multirow{2}{*}{$\begin{array}{l}\text { Capacity to decide when to edit or discard (translate from scratch) an MT } \\
\text { result }\end{array}$} & 2 & 3 & 4 & 5 \\
\hline & & & & \\
\hline Capacity to post-edit according to PE guidelines & & & & \\
\hline Capacity to post-edit up to human quality (full PE) & & & & \\
\hline Capacity to post-edit to a good enough quality (light PE) & & & & \\
\hline Capacity to pre-edit a source text according to CL & & & & \\
\hline Capacity to train \& tune an MT engine & & & & \\
\hline Capacity to identify MT output errors & & & & \\
\hline Capacity to apply the right correction strategy & & & & \\
\hline Capacity to advise when MTPE is appropriate for a text or $\mathrm{p}$ & & & & \\
\hline Capacity to provide feedback for the MT solution engineers & & & & \\
\hline Capacity to learn about new technologies & & & & \\
\hline
\end{tabular}




\section{Appendix 4}

\section{What elements does the training include?}

\begin{tabular}{|c|}
\hline Description of content profiles and text types according to MT systems \\
\hline Integration between CAT tool and MT system \\
\hline MT evaluation: automatic \& reference-based (metrics) \\
\hline MT evaluation: human (scoring, ranking, error categorization) \\
\hline MT systems: rule-based, example-based, statistical, hybrid, or neural \\
\hline PE attitude: decide when to discard and translate from scratch \\
\hline PE guidelines: exhaustive list and examples in the relevant language pair \\
\hline PE levels: light and full post-editing \\
\hline Practical PE exercises in the relevant language pair \\
\hline PE risks: under-editing, over-editing \& pseudo-editing \\
\hline PE techniques and strategies (shift, replacement, addition, deletion) \\
\hline PE technology: PE tool, ASR, touch-screen... \\
\hline Pre-editing and controlled languages \\
\hline Productivity tracking tools \\
\hline $\begin{array}{l}\text { Quality estimation or confidence scores (predictive, without post-edited gold } \\
\text { reference) }\end{array}$ \\
\hline Other \\
\hline
\end{tabular}

